\title{
Experimental Study on Submerged High-Pressure Jet and Parameter Optimization for Cavitation Peening
}

\author{
Yongfei YANG*, Wei LI**, Weidong SHI***, Chuan WANG****, Wenquan ZHANG***** \\ *Research Center of Fluid Machinery Engineering and Technology, Jiangsu University, Zhenjiang 212013, China, \\ E-mail:yyf1212@outlook.com \\ **Research Center of Fluid Machinery Engineering and Technology, Jiangsu University, Zhenjiang 212013, China, \\ E-mail: lwjiangda@ujs.edu.cn (Corresponding Author) \\ ***College of Mechanical Engineering, Nantong University, Nantong 226019, China, \\ E-mail: Wdshi@ujs.edu.cn (Corresponding Author) \\ ****College of Hydraulic Science and Engineering, Yangzhou University, Jiangsu, China, \\ E-mail: wangchuan@ujs.edu.cn \\ *****Research Center of Fluid Machinery Engineering and Technology, Jiangsu University, Zhenjiang 212013, China, \\ E-mail: $406480182 @ q q . c o m$
}

cross $^{\text {ref }}$ http://dx.doi.org/10.5755/j01.mech.26.4.27560

\section{Introduction}

Cavitation is the generation of vapour phase in liquid phase without chemical reaction, when the local pressure of the liquid is reduced below the saturated vapour pressure under a stable temperature. It is firstly found on the blade tip of propellers in 19th century, which causes noise and damage to the hydraulic machines [1-3]. The mechanism of cavitation in pumps has been investigated intensively to reduce its effects [4-6]. However, cavitation also has its positive applications in engineering fields, when it is controlled properly [7-12]. Cavitation Shot-less Peening (CSP) which is used to improve the fatigue life of metals is one of the positive functions of the cavitation impact.

Hitoshi Soyama et al. [13] conducted cavitation peening on a duralumin plate with a hole, and compared the fatigue strength of the peened plate with that without peening or treated by shot peening. It is found that, cavitation peening creates deeper residual stress on the metal surface while the surface roughness of the plate increases less than that treated by shot peening. Comparison between the various peening methods including water jet peening, laser peening and shot peening shows that cavitation peening can create a residual stress close to that of the laser peening while keeping the surface smooth, which is positive to increase the fatigue strength of stainless steels [14].

To enhance the cavitation impact of the jet, an associated submerged water jet is used for peening on SUS316L stainless steel [15]. From the experimental research, it follows that the unsteady flow characteristics of high-pressure cavitation jet has a great effect on the cavitation impact performance. Hitoshi Soyama et al. [16] captured the evolution process of cavitation jet generated by three different nozzles using high-speed photography and used pressure test paper to measure the distribution of the impact pressure of the bubble collapse at the outlet of the nozzles. It has been found that the nozzle geometry shows a great effect on the distribution and the development of the cavitation bubbles, and there is a cylindrical shaped bubble cloud near the outlet, which will break and shed off after it growing to a specific length. Two peaks of the pressure are found downstream of the nozzle outlet, which is related to shedding off phenomenon of the cavitation cloud.
Since the cavitation jet peening can only be used under submerged condition, it is difficult to be used in condition of treating components of large size. To solve this problem, an artificial submerged method is used. Hitoshi Soyama et al. [17] successfully introduced compressive residual stress into a stainless steel using a cavitation jet in air. Based on the nozzle structure, Andrea Marcon et al. optimized the stand-off distance and the nozzle configuration for the peening process $[18,19]$.

However, the mentioned studies mainly focus on the characteristic of the metal, the understanding for the nozzle geometric parameters on the unsteady flow characteristics of cavitation jet and the related impact performance is not sufficient. In this paper, the unsteady flow characteristics of high-pressure cavitation jets under three different angles are captured by high-speed photography experiments, and the growth, shedding off and collapse information is extracted from the high-speed images. Finally, it is related to the optimal standoff distance and the impact performance of the cavitation jet peening.

The paper is organised as follows. In Section 2, an experimental facility and the method are described. Experimental results are discussed in Section 3. Section 4 contains concluding remarks.

\section{Experiment facility and method}

\subsection{High speed photography}

Fig. 1 shows the high-pressure cavitation jet experiment system, which is mentioned in our former works [20]. The system uses an Italian ANNOVI REVERBERI SHP $15.50 \mathrm{~N}$ high-pressure piston pump to provide high pressure for the jet. The maximum working pressure of the piston pump is $50 \mathrm{MPa}$, the rated rotating speed is $1450 \mathrm{rpm}$, and the flow rate is $15 \mathrm{~L} / \mathrm{min}$. The water used in the experiment is pure water and the temperature is $25^{\circ} \mathrm{C}$. Y-type filter is used to prevent large particles from entering the plunger pump. A pressure relief valve and a pressure gauge are set downstream. The upstream pressure of the nozzle is controlled by adjusting the rotating speed of the plunger pump. In order to avoid the influence of the upstream pipe bending on the nozzle pressure, a stainless-steel straight pipe with 
$300 \mathrm{~mm}$ length is connected upstream of the nozzle. The jet platform is divided into two parts, a test water tank and a water storage tank. The water storage tank for supplying water to the plunger pump is located at the bottom of the test water tank. To facilitate the visual study of the submerged jet, the test tank is made of transparent material polymethyl methacrylate, which has a refractive index closed to that of water and can effectively avoid positional errors caused by photography. In order to ensure that the outlet can return to the same position after each nozzle change, the nozzle is fixed on the three-degree-of-freedom moving slide by the clamp, and the repeating positioning accuracy of the slide is 0.01-0.02 mm.

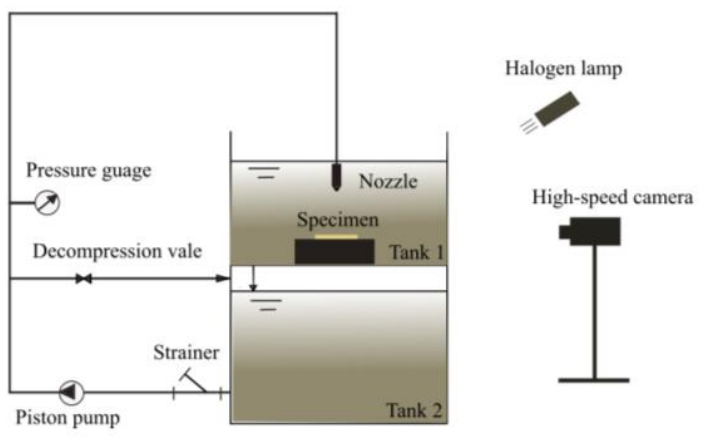

a) Schematic diagram

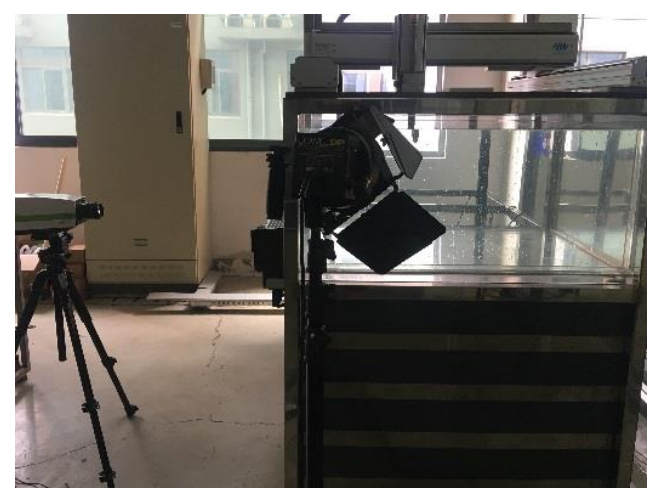

b) Photo of the experimental platform

Fig. 1 Test bench for high pressure cavitation jet

Fig. 2 shows the angular nozzle commonly used in cavitation jets. The key parameters include the throat diameter $\mathrm{d}$, the convergent angle $\beta$, the divergent angle $\alpha$, and the corresponding length of the three stages. In this paper, the effects of divergence angle on cavitation jet are studied. Three different divergent angles $\alpha=40^{\circ}, 60^{\circ}$ and $80^{\circ}$ are studied. The other parameters selected are $D=6 \mathrm{~mm}, d=1$ $\mathrm{mm}, \beta=13.5^{\circ}, L 1=5 \mathrm{~mm}, L 2=4 \mathrm{~mm}, L 3=4 \mathrm{~mm}$. Highspeed photography is conducted using OLYMPUS highspeed camera. The AC halogen lightshows pulsating intensity, which will affect the grayscale value of cavitation images. Therefore, two 200W LED lights are set in left and right sides of the tank for illumination. The transparency of the interface between the cavitation cloud and the water is relatively low and the reflection for the light is strong. As a result, the cavitation region in the photo is relatively bright. The recording area for the image is $272 \times 352$ pixels, the shooting frequency is $20000 \mathrm{fps}$, and the exposure time is $50 \mu \mathrm{sec}$. The image recording is started after the motor reaches the stable rotating speed, and the recording time of each group of data is more than 1 second. In high-frequency shooting, the interval between adjacent frames is extremely short, which is convenient for capturing the process of bubble cavitation generation, shedding off and collapse. In order to perform quantitative analysis on the spatial characteristics of the bubble clouds, the photographs were calibrated before the experiment, as shown in Fig. 3. The scale ruler is set in the axis plane of the nozzle, and the direction is perpendicular to the axis of the camera lens. The high-speed images of the cavitation jet are then captured after the calibration, and the field of view for the cameral is kept the same as that of the calibration image. The position of the lens and the nozzle are kept unchanged during the image recording. After the data is captured, the length of $60 \mathrm{~mm}$ is selected in the post-processing software ISPEED, and the number of pixels spanned is 105 pixels. From this, it is known that $1 \mathrm{~mm}$ length contains 1.75 pixels in the image and the bubble cavity length can be calculated by the pixel numbers.

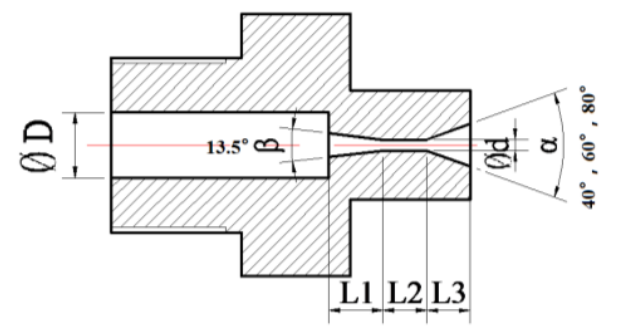

Fig. 2 Schematic diagram of the nozzle structure

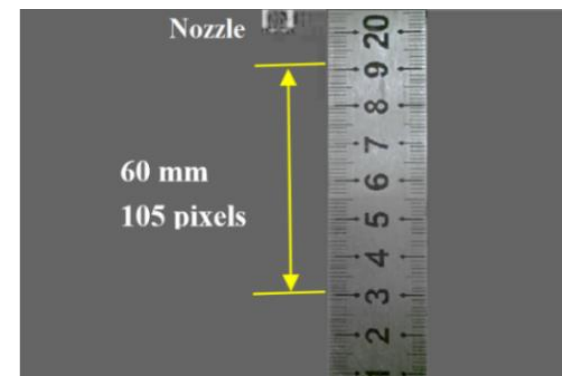

Fig. 3 Image size calibration

2.2. Erosion and peening capability test

Fig. 4 shows the facilities used for the erosion and peening test. A platform submerged in the working tank is used to fix the aluminium sample, which is kept perpendicular to the nozzle axis. To accelerate the test process and make the test period short, weak strength metal Al 1060 is used for the impingement test. The dimension of the tested Al 1060 is $100 \mathrm{~mm} \times 100 \mathrm{~mm} \times 3 \mathrm{~mm}$. Before the experiment, the Al 1060 surface is polished and cleaned. Because the fixture used to fix the nozzle tube is connected to a threeaxis slide with length scale, the standoff distance can be controlled accurately. After the high-pressure pump is started, the exposure time of the samples in the cavitation jet is recorded using a stopwatch. The samples are weighed before and after the erosion exposure with $0.001 \mathrm{~g}$ precision, so that the mass loss of the metal surface can be calculated. After the optimal stand-off distance for each nozzle is found out, the 304 stainless steel specimen with dimension of 75 $\mathrm{mm} \times 95 \mathrm{~mm} \times 3 \mathrm{~mm}$ is peened by three different nozzles, and the surface morphology as well as the grain cell structure are compared, basing on the SEM photography. 


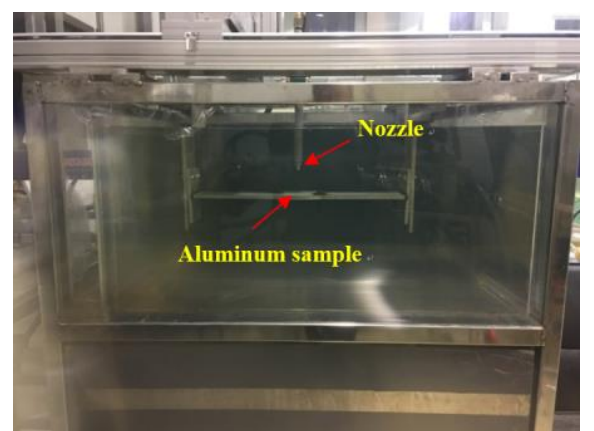

Fig. 4 Impingement on metal surface using submerged cavitation jet

\section{Results and discussion}

\subsection{Growth and collapse period of the bubbles}

To investigate the effect of nozzle geometry on cavitation performance, the cavitation clouds of nozzles with three different divergent angles are compared. Fig. 5 shows the high-speed images of the cavitation jet from nozzles with divergent angle of $40^{\circ}, 60^{\circ}$ and $80^{\circ}$ under $20 \mathrm{MPa}$. The jet from the three nozzles show similar unsteady flow characteristics periodic shedding can be observed from the images, which is in accordance with the findings of $\mathrm{Fu}$ jisawa $\mathrm{N}$ et al. [9].

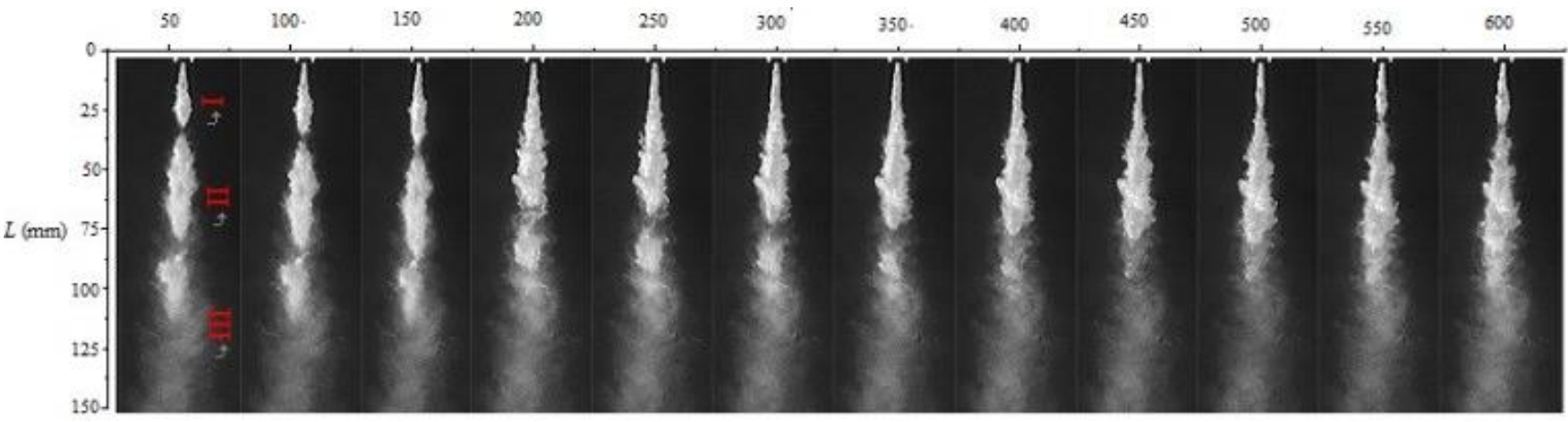

a) $40^{\circ}$

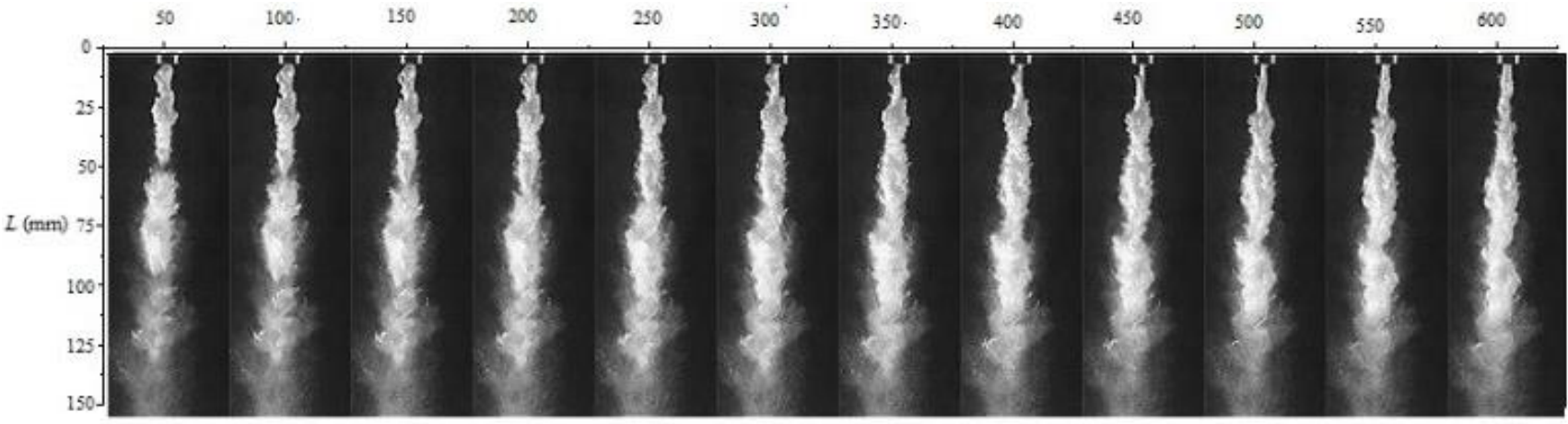

b) $60^{\circ}$

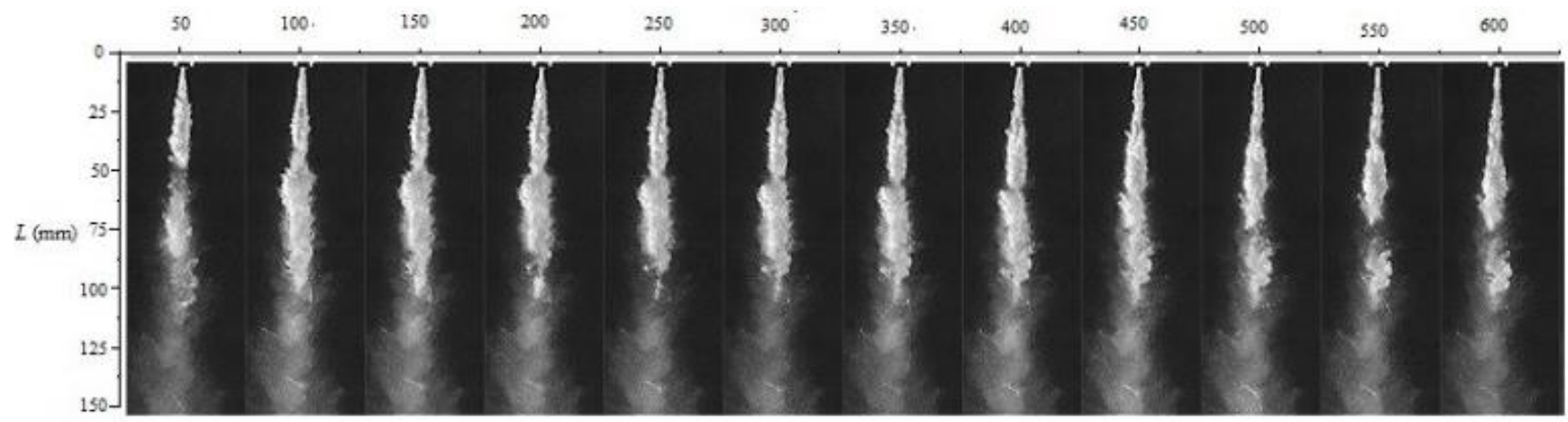

a) $80^{\circ}$

Fig. 5 High speed photography of the cavitation jet with three different nozzles

From Fig. 5, a it can be found that, the evolution of the jet cavitation shows three main stages namely cavity growth, shedding and collapse. At the beginning $(t=0 \mu \mathrm{s})$, the cavitation jet consists of three sections. The first section (I) is in the core region of the jet, where the velocity of the jet is almost constant and the entrainment of the surrounding water is slight. The boundary of this region has an extremely high velocity gradient, which forms intensive shear layer, and produces vortex rings continuously [21]. The second section (II) is the bubble collapse section, which shrinks while moving downstream. The third section (III) consists of small bubbles representing remnants of the bubble cloud. According to the research of Fujisawa $\mathrm{N}$ et al. [9], during the bubble cloud collapse, big cavitation bubbles shrink leaving bubbles with very small radius with high tempera- 
ture. After the shock, big cavitation bubbles nearby are broken into smaller bubbles. This theory explains why the profile of section III is blurred. The length of the core region increases with time until the next shedding, which occurs with $t=550 \mu$ s time interval. During the growth of the core region, the width of the bubble clouds also increases with the diffusion and the entrainment effect of the surrounded water. Observing the section of the nozzle outlet, a cylindrical cavitation cloud can be seen. This indicates that the most intensive shearing layer is not located near the nozzle outlet but at some further distance downstream. It can be found that, before the next shedding $(t=550 \mu \mathrm{s})$, the diameter of the cylindrical section is reduced. For the cavitation cloud generated by the nozzle with $60^{\circ}$ divergent angle, the cavitation cloud is obviously wider than that of other two nozzles. It can be judged that, the nozzle with $60^{\circ}$ divergent angle has the best cavitation capacity in the three nozzles, which is confirmed later in the cavitation erosion test. As the shearing process near the nozzle outlet is intensive, cavitation bubbles are generated quickly at the nozzle outlet even inside the whistle. The diameter of cylindrical section at the outlet is larger and the shedding phenomenon becomes not obvious as cavitation bubbles are supplied continuously from the nozzle outlet. Fig. 5, c shows the cavitation cloud evolution of nozzle with $80^{\circ}$ divergent angle, which is similar to that of the first nozzle. There is an obvious cylindrical section at the outlet, whose diameter varies with the growth and shedding process of the cavitation cloud. Generally, the divergence angle expert meaningful effect on the intensity and the structure of the cavitation cloud. The nozzle with $60^{\circ}$ angle shows the best performance, the cavitation peening capability of a $40^{\circ}$ nozzle is the weakest.

In order to extract the spatial distribution change of the bubble in a very short time, the photo obtained by highspeed photography is converted into a grey matrix using a MATLAB code. Since the light transmittance of the bubble is much lower than that of the liquid water, when the light of the halogen lamp is projected to the vapour-liquid interface of the bubbles, the vapour bubble reflects part of the transmitted light to the camera lens, and the higher the vapour phase concentration, the higher the image brightness can be obtained by the camera. The grayscale processed image corresponds to one grey value per pixel, the grey value is positively correlated with the brightness in the photo, and the higher the bubble density is, the higher the grey value is. On this basis, the grey matrix difference between the two photos at the adjacent time can be used to reflect the growth and disappearance of the bubble. In this paper, Frame Difference Method (FDM) analysis is carried out on the high pump pressure $(20 \mathrm{MPa})$ of $40^{\circ}$ divergence angle nozzle. As shown in Fig. 6, the development process corresponds to the first $350 \mu$ s period of Fig. 5, a. The scale value in the figure is proportional to the growth rate of the bubble cloud, the positive value indicates the growth of the bubble cloud, and the negative value indicates the collapse of the bubble cloud. The blue area indicated by the dotted line in the figure indicates the main area of the bubble collapse. As it can be seen from Fig. 5, a, the main collapse follows disintegration of the largest bubbles in zone II and takes place at the rear end of the shed cavitation cloud. This is consistent with the research conclusion of Fujisawa N et al. [9], Fujisawa N. recorded the shock wave generated by the collapse of the highpressure submerged cavitation jet by the schlieren technique. The shock wave is mainly located at the rear end of the shed bubble cloud.

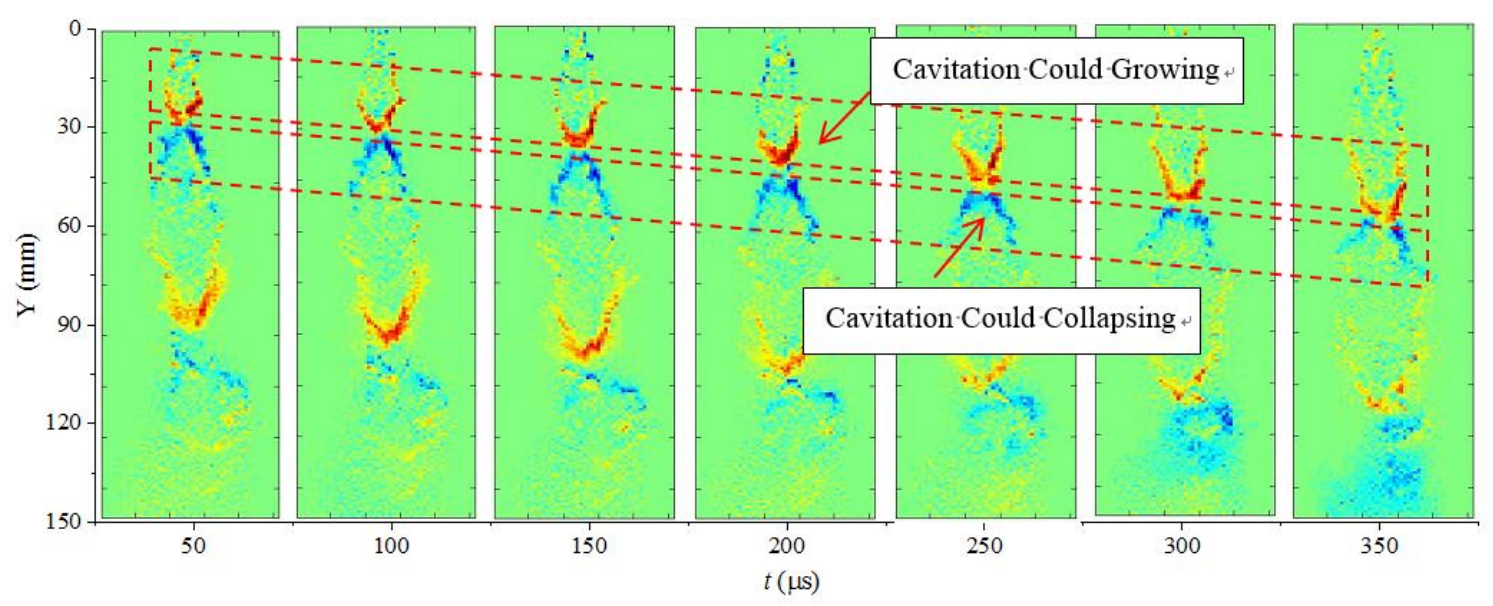

Fig. 6 FDM diagram of the cavitation cloud from a $40^{\circ}$ nozzle

\subsection{Effect of nozzle geometry and stand-off distance}

The cavitation peening capacity of the nozzles can be enhanced by optimizing the nozzle geometry while the upstream pressure and the standoff distance also have a great effect on the performance of cavitation jet [22]. Fig. 7 shows the mass loss of the aluminium by the cavitation erosion with the jet under different standoff distances. The upstream pressure of the nozzles is controlled stable as $20 \mathrm{MPa}$ and the impingement time is $60 \mathrm{~min}$. It can be found that with the short standoff distance, the erosion of the aluminium is weak for all the nozzles, although the impact force of the high momentum water is higher when the nozzle is closed to the metal surface. With the incensement of the standoff distance, the erosion rate rises gradually and then decrease quickly after it reaches the peak value. The optimal standoff distance for the $60^{\circ}$ nozzle $(72 \mathrm{~mm})$ is larger than that of the other nozzles $(66 \mathrm{~mm})$. By comparing the peak value of the mass loss of the aluminium eroded using the three different nozzles, it can be found that the erosion efficiency of nozzle with $60^{\circ}$ divergence angle is obviously higher than that of the other two nozzles. This is in consistence with the result of the high-speed photography experiment, as the nozzle with the optimal divergence angle generates longer and wider cavitation bubble clouds using the same pump pressure. When the $60^{\circ}$ nozzle works with the 
optimal standoff distance, the aluminium mass loss reaches around $550 \mathrm{mg}$ after being impinged for $60 \mathrm{~min}$. For the nozzle with $80^{\circ}$ divergent angle, the highest erosion rate of the aluminium specimen is around $35 \mathrm{mg}$, while that for the $40^{\circ}$ nozzle reaches only $7 \mathrm{mg}$. It seems that the nozzle divergence angle has only a slight effect on the optimal standoff distance, while its effect on the erosion performance of the cavitation jet is great. It is already proved that, divergent type nozzle has a better cavitation performance than convergent and cylindrical nozzles, as the divergent whistle enhances the vortex formation in the shear layer with a high velocity gradient. The existence of the trumpet shape outlet prevents the pressure supply from the surrounded water to the low-pressure shear layer. In case of the nozzle with $40^{\circ}$ divergence angle, the outlet is similar to that of the cylindrical nozzle. At the same time, the divergent section of the nozzle with small divergence angle works as an extension

of the throat section of the nozzle, which decreases the penetration ability of the jet under the same upstream pressure. The effect of standoff distance on the erosion rate is mainly caused by the change of bubble collapse location. As mentioned by H. Soyama et al. [23], when the cavitation jet impinges on the metal surface, the cavitation bubbles will be carried by a vortex ring that expands close to the wall and collapses while the surrounding pressure recovers. According to the impingement experiment on submerged jet, the standoff distance affects the pressure distribution and the vortex structure near the surface. If the standoff distance is too close to the metal surface, the vortex will move away from the surface and the shock wave created by the cavitation collapse will impinge the metal surface with lower power density. On the other way, when the standoff distance is too large, most of the bubbles will collapse before reaching the metal surface, and the erosion ability will be reduced.

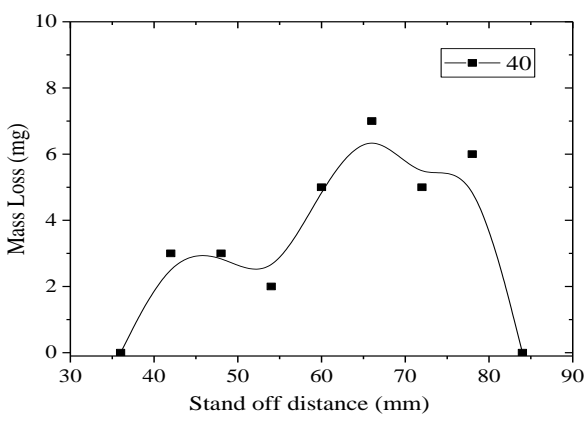

a) $40^{\circ}$ divergent angle

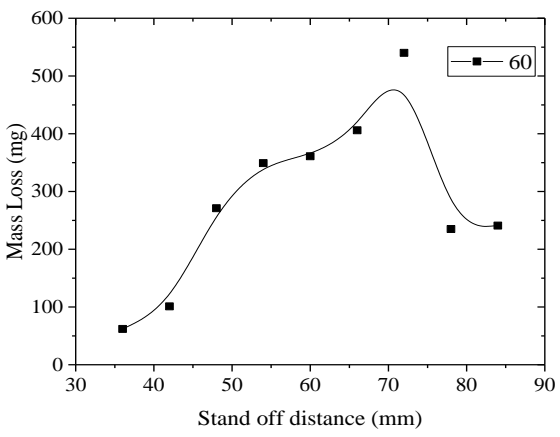

b) $60^{\circ}$ divergent angle

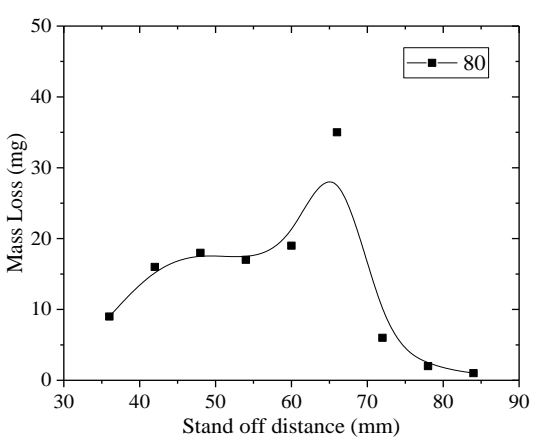

c) $80^{\circ}$ divergent angle

Fig. 7 Mass loss of the aluminium specimen at different standoff distances after 60 min impingement

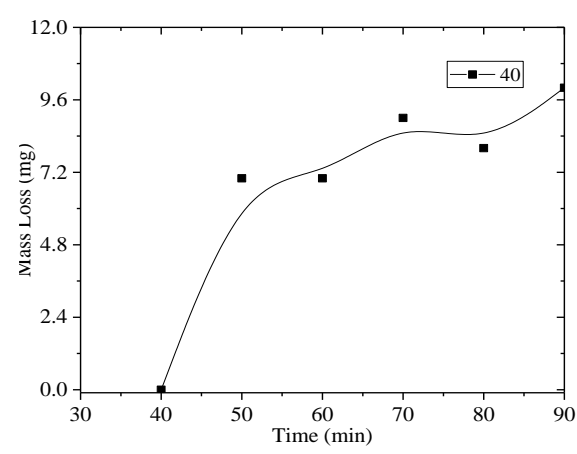

a) $40^{\circ}$ divergence angle

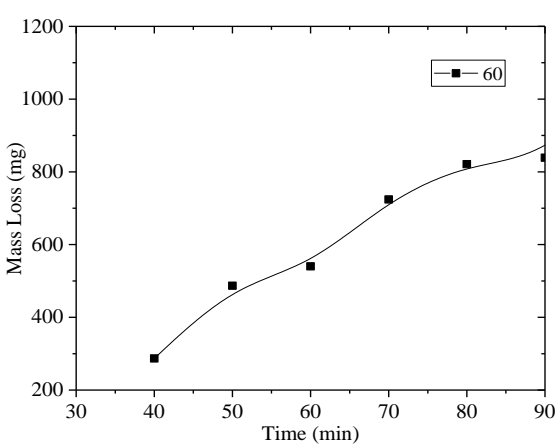

b) $60^{\circ}$ divergence angle

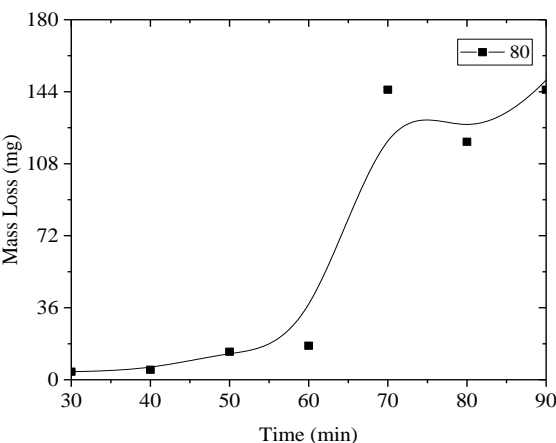

c) $80^{\circ}$ divergence angle

Fig. 8 Mass loss of the Aluminium with different impingement time at the optimal standoff distance

To investigate the cavitation erosion rate, aluminium is tested using the mentioned three nozzles with different time. The tested time duration is from $30 \mathrm{~min}$ to $90 \mathrm{~min}$ with an interval of $10 \mathrm{~min}$. From Fig. 8 it can be found, as the impingement time increases, the mass loss rises while the erosion rate decreases. The non-monotonic character of the mass loss in time can be explained by an uncertainty of the experiment (Figs. 8, a and c). When the nozzle type, pressure, stand-off distance and impinged time are kept unchanged, the mass loss must be closed. However, some uncertainty can happen e.g. some small defect was hidden under the surface of the material and accelerates the mass loss slightly. In general, the mass loss has an increasing tendency with the increase of the impinging time and the effect of the uncertainty can be ignored. When the exposure time is lesser than $40 \mathrm{~min}$, the aluminium specimen shows almost no mass loss except in the case of the $60^{\circ}$ nozzle. Before the mass loss starts to occur, the shock wave and micro jet impact on the metal cause plastic deformation. During this process, compressive residual stress is formed on the metal surface. This erosion stage is defined as erosion incubation. The incubation period is found to have a positive effect on the metal fatigue strength due to hardening the metal surface as the grain structure is changed by the shock. This period is usually used in cavitation peening to enhance the surface performance of metals. After the incubation period there is a sudden rise of the mass loss, because the fatigue limit has been already reached for most of the surface grains. After the accelerated mass loss period, the mass loss rate slows down again, because the surface characteristic of the mental 
is changed and the new surface shape affects the cavity dynamics. Meanwhile the deep crates can damp the pressure wave of the cavitation and reduces the impact.

\subsection{Cavitation peening on stainless steel}

To verify the performance of the jet parameters that optimized for the cavitation peening, 304 stainless steel samples have been tested and analysed. Fig. 9 shows the surface profile of 304 stainless steel that has been peened using the nozzles with three different divergence angles. The time period for the peening was 30min and the stand-off distance was set as the optimal distance for each nozzle. From the figures, pits with different size can be identified on the surface of all the peened samples. The nozzle with $40^{\circ}$ angle shows less pits on the metal surface, indicating that the concentration of cavitation bubbles generated by this nozzle is lower than in the case of two other nozzles. Since the metal surfaces peened by the second and the third nozzles are both filled with large and small pits, it's difficult to assess the

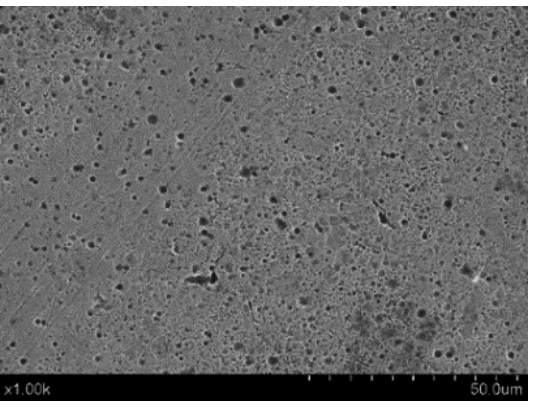

a

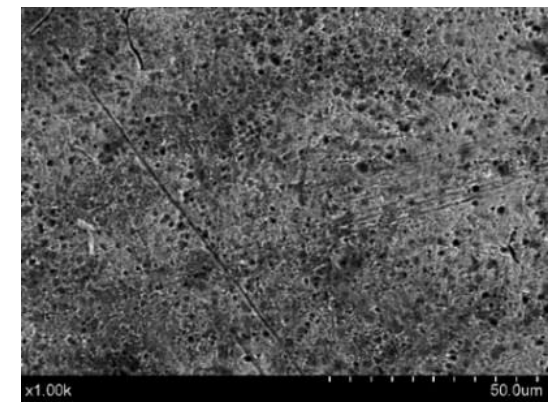

b peening performance of these two nozzle configurations by comparing the surface profiles.

Fig. 9 shows SEM photo of the section surface, from which the grains under the peened surface of the metal can be seen clearly. From Fig. 10, a it can be found that before cavitation jet peening the stainless steel has an austenite grain structure with little twins. After peening, as shown in Fig. 10, b to d, a layer filled with twins is generated clear to the peened surface, which indicates that shock wave and the micro-jet produced by the cavitation collapse have an obvious impact on the metal surface. Comparing these photos, it can be found that the $60^{\circ}$ nozzle shows the highest effectiveness of cavitation peening. The grain cells near the surface of the metal peened using $60^{\circ}$ nozzles are much smaller than those of the other two samples, indicating that the grain cells get refined by the cavitation peening process. Also, the $60^{\circ}$ nozzle produces thicker twin layer than the other two, which can increase the hardness and compressive residual stress in the layer under the surface.

Fig. 9 SEM photograph of metal surface peened with different nozzles: a) Peened using $40^{\circ}$ nozzle; b) Peened using $60^{\circ}$ nozzle; c) Peened using $80^{\circ}$ nozzle

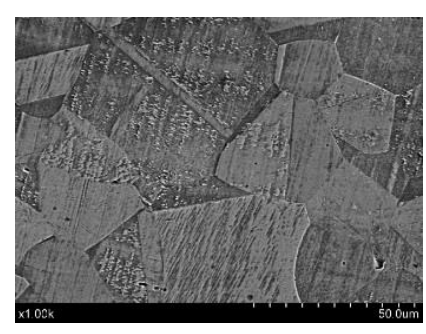

a

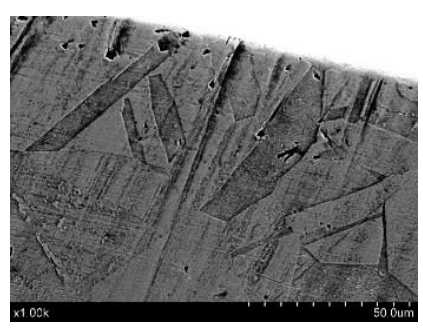

b

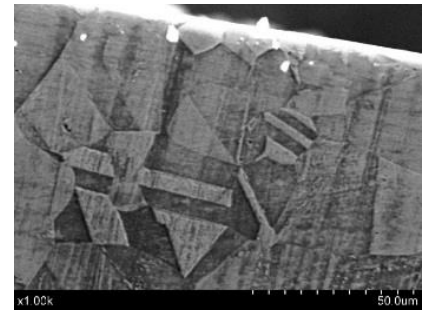

$\mathrm{C}$

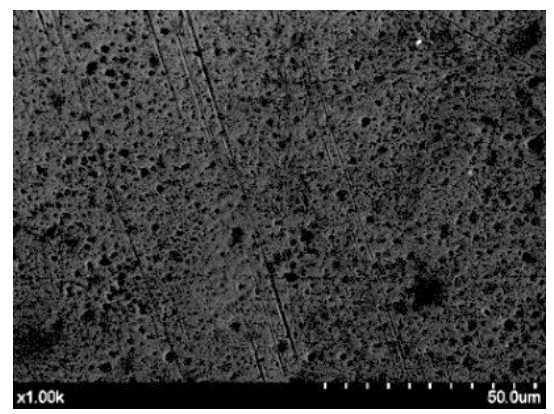

$\mathrm{C}$

Fig. 10 SEM photograph of grain cells on the section surface peeninged with different nozzles: a) Without peening; b) Peened using $40^{\circ}$ nozzles; c) Peened using $60^{\circ}$ nozzles; d) Peened using $80^{\circ}$ nozzle

\section{Conclusion}

Unsteady flow pattern characteristics of high pressure submerged cavitation jet have been investigated using high-speed photography. The evolution of the growth, development, shedding and collapse period of the cavitation bubbles have been observed. The stand-off distance as well as the nozzle geometry have been optimized using the erosion test on Al1060 and peening of 304 stainless steel. The research results are as follows:

1. The outlet divergence angle of the convergentdivergent type nozzle has a great influence on the cavitation jet. When the nozzle expansion angle is too large or too small, it will result in poor cavitation performance and the peening capability. It is found that there exists an optimal value for the divergence angle around $60^{\circ}$, so that the cavitation concentration of the submerged cavitation jet can reach the highest level and the cavity length is the largest.

2. When the pressure is stable, the distance of the nozzle from the target has a very obvious effect on the cavitation erosion performance of the submerged high-pressure water jet. As the standoff distance increases from $36 \mathrm{~mm}$ to $84 \mathrm{~mm}$, the mass loss of the impinged metal increases, and decreases rapidly after reaching the best distance. For different nozzles, the best target distance is different, but in the same range, and the nozzle with the highest cavitation performance has the longest best standoff distance.

3 . When the 304 stainless steel is peened by a highpressure cavitation jet, small pits with different size appear on the metal surface, and the nozzle with larger divergent angle creates more pits. The grain cell of the stain less steel without peening shows an austenite grain structure, while twins appears after the metal is peened. Nozzle with $60^{\circ}$ divergence angle shows the best peening performance, which 
refines the grain size obviously and creates deepest twin layer under the metal surfaces.

\section{Acknowledgement}

The work was sponsored by the National Natural Science Foundation of China (No.51679111, No.51409127 and No.51579118), National Key R\&D Program Project (No.2017YFC0403703), PAPD, Six Talents Peak Project of Jiangsu Province (No.HYZB-002), Key R\&D Program Project in Jiangsu Province (No.BE2016319, No.BE2017126), Natural Science Foundation of Jiangsu Province (No.BK20161472, No.BK20160521), Science and Technology Support Program of Changzhou (No.CE20162004), Key R\&D Program Project of Zhenjiang (No.SH2017049), and Scientific Research Start Foundation Project of Jiangsu University (No.13JDG105), National Natural Science Foundation of China (Grant No.51609105 and No.51979240), Jiangsu Province Universities Natural Sciences Foundation (Grant No.16KJB570002), China Postdoctoral Science Foundation (Grant No.2016M601738 and 2018T110458).

\section{References}

1. Friedrichs, J.; Günter Kosyna. 2002. Rotating cavitation in a centrifugal pump impeller of low specific speed, Journal of Fluids Engineering 124(2): 356-362. http://dx.doi.org/ 10.1115/1.1457451.

2. Čdina, M. 2003. Detection of cavitation phenomenon in a centrifugal pump using audible sound, Mechanical systems and signal processing 17(6): 1335-1347. https://doi.org/10.1006/mssp.2002.1514.

3. Adamkowski, A.; Henke, A.; Lewandowski, M. 2016. Resonance of torsional vibrations of centrifugal pump shafts due to cavitation erosion of pump impellers, Engineering Failure Analysis 70:56-72. https://doi.org/10.1016/j.engfailanal.2016.07.011.

4. Tan, L.; Zhu, B. S.; Cao, S. L.; et al. 2014. Influence of prewhirl regulation by inlet guide vanes on cavitation performance of a centrifugal pump, Energies 7(2):10501065.

https://dx.doi.org/10.3390/en7021050.

5. Bai, L.; Zhou, L.; Jiang, X. P.; Pang, Q. L.; Ye, D. X. 2019. Vibration in a multistage centrifugal pump under varied conditions, Shock and Vibration, 2057031. https://doi.org/10.1155/2019/2057031.

6. Bai, L.; Zhou, L.; Han, C.; Zhu, Y.; Shi, W. D. 2019. Numerical study of pressure fluctuation and unsteady flow in a centrifugal pump, Processes 7(6), 354. https://doi.org/10.3390/pr7060354.

7. Howard, S. C.; Graham, F. C.; Hochrein A.; et al. 1978. Research and development of a cavitating water jet cleaning system for removing marine growth and fouling from U. S. Navy ship hulls[J]. Cavitation. https://apps.dtic.mil/docs/citations/ADA065463.

8. Arola, D.; Alade, A. E; Weber, W. 2006. Improving fatigue strength of metals using abrasive waterjet peening, Machining Science \& Technology 10(2):197-218. http://doi.org/10.1080/10910340600710105.

9. Fujisawa, N.; Fujita, Y.; Yanagisawa, K.; et al. 2018. Simultaneous observation of cavitation collapse and shock wave formation in cavitating jet, Experimental Thermal \& Fluid Science 94:159-167. https://doi.org/10.1016/j.expthermflusci.2018.02.012.

10. Soyama, H.; Kusaka, T.; Saka, M. 2001. Peening by the use of cavitation impacts for the improvement of fatigue strength, Journal of Materials Science Letters 20(13):1263-1265. https://doi.org/10.1023/A:1010947528358.

11. Soyama, H.; Asahara, M. 2000. Improvement of the corrosion resistance of a carbon steel surface by a cavitating Jet, Journal of Materials Science Letters 19(13):1201-1205. https://doi.org/10.1023/A:1006731831248.

12. Yamauchi, Y.; Soyama, H.; Adachi, Y.; et al. 2008. Suitable region of high-speed submerged water jets for cutting and peening, JSME International Journal Series B, 38(1), 31-38. https://dx.doi.org/10.1299/jsmeb.38.31.

13. Soyama, H.; Takeo, F. 2016. Comparison between cavitation peening and shot peening for extending the fatigue life of a duralumin plate with a hole, Journal of Materials Processing Technology 227:80-87. https://doi.org/10.1016/j.jmatprotec.2015.08.012.

14. Soyama, H. 2019. Comparison between the improvements made to the fatigue strength of stainless steel by cavitation peening, water jet peening, shot peening and laser peening, Journal of Materials Processing Technology 269:65-78.

https://doi.org/10.1016/j.jmatprotec.2019.01.030.

15. Soyam,a H; Mikami, M. 2007. Improvement of fatigue strength of stainless steel by using a cavitating jet with an associated water jet in water, Key Engineering Materials 353-358:162-165.

https://doi.org/10.4028/www.scientific.net/KEM.353358.162 .

16. Soyama, H.; Yoshiaki, Yanauchi; Kazunori, Sato; et al. 1996. High-speed observation of ultrahigh-speed submerged water jets, Experimental Thermal \& Fluid Science 12(4):411-416. https://doi.org/10.1016/0894-1777(95)00124-7.

17. Soyama, H.; Kikuchi, T.; Nishikawa, M.; et al. 2011. Introduction of compressive residual stress into stainless steel by employing a cavitating jet in air, Surface \& Coatings Technology 205(10): 3167-3174. https://doi.org/10.1016/j.surfcoat.2010.11.031.

18. Marcon, A.; Melkote, S. N.; Castle, J.; et al. 2016. Effect of jet velocity in co-flow water cavitation jet peening, Wear 360-361: 38-50. https://doi.org/10.1016/j.wear.2016.03.027.

19. Marcon, A.; Melkote, S. N.; Yoda, M. 2018. Effect of nozzle size scaling in co-flow water cavitation jet peening, Journal of Manufacturing Processes 31:372-381. https://doi.org/10.1016/j.jmapro.2017.12.002.

20. Yang, Y.; Li, W.; Shi, W.; Zhang, W.; A El-Emam, M. 2019. Numerical investigation of a high-pressure submerged jet using a cavitation model considering effects of shear Stress, Processes 7(8), 541. https://doi.org/10.3390/pr7080541.

21. Liu, H.; Kang, C.; Zhang, W.; et al. 2017. Flow structures and cavitation in submerged waterjet at high jet pressure, Experimental Thermal and Fluid Science 88: 504-512. https://doi.org/10.1016/j.expthermflusci.2017.07.003.

22. Li, D.; Kang, Y.; Wangm X.; et al. 2016. Effects of nozzle inner surface roughness on the cavitation erosion 
characteristics of high speed submerged jets[J]. Experimental Thermal \& Fluid Science, 74: 444-452.

https://doi.org/10.1016/j.expthermflusci.2016.01.009.

23. Soyama, H. 2019. Fundamentals and applications of cavitation peening comparing with shot peening and laser peening, In International Conference on Advanced Surface Enhancement: 76-87.

https://doi.org/10.1007/978-981-15-0054-1_9.

Y. Yang, W. Li, W. Shi, Ch. Wang, W. Zhang

EXPERIMENTAL STUDY ON SUBMERGED HIGHPRESSURE JET AND PARAME-TER OPTIMIZATION FOR CAVITATION PEENING

S u m m a r y

To increase the performance of high pressure submerged cavitation jet that has been used for cavitation peening, the effect of stand-off distance and the nozzle geometry on the impact capacity is investigated and optimized. High speed photography of the cavitation bubble clouds taken to reveal the unsteady characteristics of the cavitating jet. The impact ability of the jet with different nozzles and standoff distance is tested using Al 1060 at first, and the optimized jet is used then for cavitation peening on 304 stainless steel. The surface profile as well as the grain structures before and after peening using different nozzles are observed from SEM images. It is found that, the divergent angle of the nozzle has a great effect on the impact capability of the submerged high-pressure jet, which is important for improving the peening efficiency. In the nozzles with divergent angle $40^{\circ}, 60^{\circ}$ and $80^{\circ}$, the $60^{\circ}$ nozzle shows the best performance. After peening, grain cells under the metal surface are changed and a twin layer is formed. The current research reveals the transient characteristics of the submerged cavitation jet and main factors that affect its impact rate, which provides guide for the nozzle design and application for the high-pressure cavitation jet peening.

Keywords: cavitation; submerged jet; high-speed photography; peening; nozzle.

Received September 30, 2019 Accepted August 24, 2020

This article is an Open Access article distributed under the terms and conditions of the Creative Commons Attribution 4.0 (CC BY 4.0) License (http://creativecommons.org/licenses/by/4.0/). 